\title{
L'avaluació confitada, el discurs actual sobre el paper de la tecnologia en educació i el control de danys del sistema educatiu català quan els fets ja no compten
}

\section{Mauro Valenciano Oller *}

\section{Resum}

En aquest text ordeno algunes consideracions sobre els efectes en l'ensenyament obligatori de les mesures per tractar de fer front la situació generada pel COVID-19 i les polítiques del confinament. Faig esment de mesures anunciades com pedagògiques, però apunto la qüestió que són de fet mesures principalment amb una marcada arrel econòmica i política. Una de les procedències d'aquestes consideracions són alguns comentaris dirigits a l'alumnat de la classe de l'assignatura Economia de l'educació durant el confinament. Una segona procedència d'aquestes reflexions serà la revisió de les idees recollides per un estudi de cas, destacant alguns dels punts relacionats amb l'avaluació. Concretament, aquesta segona precedència remet a les meves experiències professionals en un centre públic de secundària a partir del 13 de març de 2020, així com també un comentari centrat en el discurs sobre l'ús de la tecnologia. Després, per pensar els mals d'escola contemporanis proposo un passeig per les aules a partir de diferents referències bibliogràfiques, a mode això últim de selecció de lectures, que en el futur podria acabar esdevenint una guia de lectura. Per enllestir el text, culmino la meva anàlisi amb alguns comentaris finals, concretament algunes notes sobre la figura del professor, de l'intel.lectual i del filòsof en els nostres temps.

\section{Paraules clau}

Avaluació educativa, polítiques del confinament, neoliberalisme, tecnologia, escola contemporània, teoria de l'educació.

Recepció original: 31 de juliol de 2020

Acceptació: 18 de setembre de 2020

Publicació: 16 de desembre de 2020

\section{Nota inicial sobre el títol del text, seguit d'un esbós sobre les meves intencions $^{1}$}

\author{
It is the job of teachers, and also parents, to prepare children for the world \\ which they will inherit as adults. \\ Alex Standish, The False Promise of Global Learning (2012, p. 27) \\ Cuando éstos [los padres] hacen que el niño se adapte a las pautas de con- \\ ducta de la familia, incluyen al hijo en el mundo social de la familia y de la \\ sociedad. De manera que exigir es incluir. No exigir es abandonar al niño, con
}

(*) Llicenciat en Ciències de l'Activitat Física i l'Esport. Màster en Ciutadania i Drets Humans: Ètica i Política (Universitat de Barcelona / Universitat de Girona). Actualment treballa com professor d'Educació Física a secundària, i també com professor associat a la Facultat d'Educació de la Universitat de Barcelona. És colllaborador del Grup de Recerca en Pensament Pedagògic i Social (GREPPS). A més a més, és Entrenador Superior de Basquetbol i porta més de 25 anys entrenant a diferents categories del bàsquet català. Ha publicat nombrosos articles i vuit llibres sobre temàtica esportiva i educativa. El títol del darrer llibre és Phil Jackson. El maestro zen (Ediciones JC, 2017). És membre fundador de I'Associació Societat Científica Metaescrits, i també membre fundador del grup d'estudi Esportivàrius. El seu treball de tesi doctoral es titula «Reglamentació, educació i minibàsquet: Un estudi històric i comparatiu», que serà defensat durant l'any 2021. Adreça electrònica: mvalenciano@ub.edu.

(1) Una primera versió del treball va ser compartit amb alguns col-legues professionals prèviament a la presentació en una seminari a la Universitat de Barcelona el 13 de juliol de 2020, seminari que portava per títol «Lectura Confi(n)ada 2.0». Aquests col-legues formen part del nostre grup d'estudi Esportivàrius. Durant la reunió periòdica que vàrem organitzar el 16 de maig de 2020, vaig presentar un estudi de cas referent al centre de secundària en el qual treballo, amb accent en els aspectes d'avaluació. A banda d'aquest deute intel-lectual, també m'he nodrit d'altres circumstàncies, espais formatius i nocions per completar aquest esbós de l'estat de l'avaluació en educació en temps de confinament. Aquests orígens intel.lectuals els explicitaré a mesura que presenti l'estructura i contingut del text. Tanmateix, vull fer notar que aquest text que apareix ara publicat, tret d'algunes lleugeres modificacions, va ser compartit amb els assistents la tercera i última sessió del seminari abans esmentat sota el títol «Avaluació confitada i control de danys en el sistema públic català d'ensenyament obligatori: quan els fets ja no compten». Aquest seminari va ser virtual organitzat pel GREEPS (Grup de Recerca en Pensament Pedagògic i Social) de la UB. 
el consiguiente peligro de que se convierta en un marginado. Cuando los padres cuentan con que el niño se adecue a lo exigido, lo están preparando para la vida.

Inger Enkvist, Repensar la educación (2006, p. 16-17)

En la posmodernidad de fin de siglo en España, el Estado no está en construcción sino en descomposición. La discriminación, usada como tabú, no como concepto de definir y precisar, ha quedado desactivada retóricamente, por lo que no es admisible selección alguna ni siquiera por el esfuerzo, el talento o la capacidad, innecesaria en un Estado en descomposición para el que el sistema público de educación no desempeña función formativa sino meramente policial.

José Sánchez Tortosa, El culto pedagógico (2019, p. 283-284)

Marx comprendió muy bien que la tecnología, al margen de sus repercusiones económicas, crea las estructuras con las que la gente percibe la realidad, y que estas estructuras son la clave para entender las diferentes formas de vida social y mental.

Neil Postman, Tecnópolis: La rendición de la cultura a la tecnología $(2018$, p. 41)

El títol d'aquest text pren com punt de partida el Seminari Lectura Confi(n)ada dut a terme els mesos de maig, juny i juliol de 2020, organitzat pel GREPPS, a la Universitat de Barcelona. La idea inicial per anomenar aquest article me la va suggerir el terme confi(n)ada que apareixia en el títol del seminari. De seguida vaig albirar la possibilitat d'un joc de paraules per parlar del tema de l'avaluació educativa i, més concretament, de les mesures d'avaluació durant la tercera avaluació del curs 2019-20, coincidint amb els mesos de confinament pel COVID-19. De fet, un cop vaig mirar-me el rètol del Seminari que s'havia enviat en algun dels correus del Departament de Teoria i Història de l'Educació, vaig veure que ja algú -en concret, el professor Enric Prats i Gil- havia previst aquesta idea: confinada, confitada... Malgrat vaig descobrir que no havia estat el primer en tenir l'enginy d'imaginar aquest joc de paraules entre confinada i confitada, vaig decidir mantenir la denominació del text. Penso que parlar d'avaluació confitada recull fidelment la idea del que hem estat fent amb l'avaluació durant aquests darrers mesos, i fins i tot podríem dir: durant molt més temps abans. Aquest «molt més temps» es connecta, certament, amb l'aire arendtià de la cita inicial d' Alex Standish.

Al costat d'aquest motiu, un dels altres elements que van il-luminar i guiar alguns dels passos d'aquestes reflexions va ser una lectura suggerida dins de l'esmentat Seminari, concretament el text pendent de publicació titulat «El Trieste cosmopolita como registro pedagógico de Europa: impunidad e inmunidad en Magris y Drndic», que està signat per Enric Prats i Clara Domènech. En la pàgina 7 d'aquest text apareix la següent afirmació: «la impunidad es el valor en alza en tiempos de posverdades, cuando los hechos ya no cuentan». Penso que la frase resulta idònia per perfilar l'horitzó ètic del meu text, i per això l'agafo al peu de la lletra: quan els fets ja no compten. Però aleshores... què vol dir exactament per mi això «quan els fets ja no compten»? Sigmund Freud parla en el seu text El porvenir de una ilusión (1927) d'un assumpte que al meu entendre connecta de manera estreta i directa amb aquesta idea que els fets comptin / no comptin. És una cita extensa, però que penso que paga la pena posar-la de manera íntegra per fonamentar la meva idea que els fets comptin / no comptin. Penso que aquest text de Freud recull un valuós missatge pedagògic:

Se hallará como el niño que ha abandonado el hogar paterno, en el cual se sentía seguro y dichoso. Pero, ¿no es también cierto que el infantilismo ha de ser vencido y superado? El hombre no puede permane- 
cer eternamente niño; tiene que salir algún día a la vida, a la dura «vida enemiga». Esta sería la «educación para la realidad». ¿Habré de decirle todavía que el único propósito del presente trabajo es señalar la necesidad de tal progreso?

Teme usted, seguramente, que el hombre no pueda resistir tan dura prueba. Déjenos esperar que sí. La consciencia de que sólo habremos de contar con nuestras propias fuerzas nos enseña, por lo menos, a emplearlas con acierto. Pero, además, el hombre no está ya tan desamparado. Su ciencia le ha enseñado muchas cosas desde los tiempos del Diluvio y ha de ampliar aún más su poderío. Y por lo que respecta a lo inevitable, al destino inexorable, contra el cual nada puede ayudarle, aprenderá a aceptarlo y soportarlo sin rebeldía. ¿De qué puede servirle el espejismo de vastas propiedades en la Luna, cuyas rentas nadie ha recibido jamás? Cultivando honradamente aquí en la Tierra su modesto pegujal, como un buen labrador, sabrá extraer de él su sustento. Retirando sus esperanzas del más allá y concentrando en la vida terrena todas las energías así liberadas, conseguirá, probablemente, que la vida se haga más llevadera a todos y que la civilización no abrume ya a ninguno, y entonces podrá decir, con uno de nuestros irreligiosos:

El cielo lo abandonamos a los gorriones y a los ángeles. (Freud, 2007, p. 2988)

A més a més d'aquesta vigorosa referència pedagògica (una autèntica lliçó de vida, i mi m'agrada especialment el moment en què anomena «la dura vida enemiga») evocada en aquest text psicoanalític, com és habitual en els treballs que he anat presentant en la Facultat des de fa un temps, faré una alineació habitual. El meu pla de partit -com entrenador i també com escriptor- és sortir a l'atac. En aquest text mostraré una de les meves jugades habituals: sovint em nodreixo de les experiències professionals que he viscut en diversos àmbits. La reflexió ètica que em plantejo en les següents pàgines procuro articular-la en relació a una sèrie d'elements de la meva praxi professional. Gràcies al treball d'elaboració escrita del text, aquest exercici em permet pensar-me en els meus rols professionals, tot revisant la meva mirada. Per una banda, la meva dedicació docent a l'àmbit formal, tant a secundària com també a la universitat; per una altra banda, i en relació a l'àmbit de l'educació no formal, el bagatge de 25 anys entrenant equips de bàsquet. En quan a la temàtica, en aquesta ocasió he volgut agafar-li el pols a l'assumpte de l'avaluació com professor de secundària, deixant de costat el mateix assumpte en la vessant universitària, que bé podria merèixer un text propi, independent.

L'anàlisi i interpretació dels discursos generats al voltant de l'avaluació a secundària a partir del 13 de març de 2020 serviran per guiar bona part del text. Aquest serà, doncs, un dels punts que desenvoluparé, i que estarà mediatitzat per la presentació d'un estudi de cas (l'anàlisi de l'avaluació en el centre de secundària on treballo) en la reunió del 16 de maig del grup d'estudi Esportivàrius. Aquí presentaré alguns fets destacables d'aquest estudi de cas que vaig preparar. Al costat d'això també presentaré algunes notes que vaig prendre després de parlar en una classe d'Economia de l'educació en la qual vaig esbossar algunes qüestions educatives (i econòmiques) al voltant del temps de confinament, de la docència virtual a nivell d'institut i del tema de les desigualtats educatives (i econòmiques) del alumnes en temps de confinament.

Per completar les idees mostrades tant en relació a la meva vivència de l'avaluació al centre de secundària on treballo, així com també les reflexions que vaig poder plantejar dins de l'assignatura d'Economia de l'educació, inclouré un passeig per determinades referències bibliogràfiques que tracten la vida a les aules i que toquen, d'una manera o d'una altra, la qüestió de l'avaluació dels alumnes. Aquesta tria de textos que presentaré responen a un antic desig de realitzar una mirada atenta i una reflexió escrupolosa al voltant d'una munió de treballs que he anat llegint durant aquests darrers anys. A fi de confegir aquesta selecció, em centraré en recollir les referències d'alguns dels Ilibres que con- 
sidero més destacables de les publicacions aparegudes entre 2000 i 2020 . Avanço al lector que la selecció de textos que he fet parteixen d'una intenció no sistemàtica, i per tant alguns títols que es podrien considerar molt destacables d'aquest període de publicació potser hauran quedat al marge. Per tant, animo a que a ningú se li faci estrany ni li pesi en l'esperit adonar-se de les meves afinitats i gustos. Si bé en aquesta ocasió assajo una selecció de títols, penso que aquest esbós inicial podria esdevenir, més endavant potser, una futura guia de lectura. Ja per tancar aquest text, presentaré alguns comentaris finals, així com un apunt final.

\section{Reflexions des de la universitat sobre avaluació dins el sistema públic d'ensenyament obligatori}

La universitat encara pot tenir una dimensió d'espai per la reflexió, malgrat algunes crítiques severes que aquesta institució ha sofert (Llovet, 2011; Valdecantos, 2014; Furedi, 2018). Quan pensem en termes del funcionament del sistema educatiu, la universitat i tots aquells que en formem part podem desenvolupar una crítica envers la manera com es treballa en el món de l'educació. La universitat, aleshores, pot esdevenir un espai de reflexió sobre el sistema educatiu, una instància «meta-reflexiva» (reflexió sobre la reflexió) respecte el conjunt del sistema educatiu. En aquest sentit, exposaré algunes de les idees que vaig presentar durant la classe del passat 19 de maig de 2020, concretament amb les alumnes del grup T1 de l'assignatura d'Economia de l'educació del Grau de Pedagogia a la Universitat de Barcelona.

En els darrers mesos hem sentit a parlar molt en els mitjans de comunicació que la prioritat de l'administració educativa catalana (i en certa manera també de l'espanyola) era garantir que no augmentessin les desigualtats entre els alumnes que disposen d'accés a Internet i a maquinari adequat (ordinador personal, tauleta), i els que no tenen connectivitat ni maquinari adient. Aquesta ha estat la cantarella que hem sentit de manera freqüent en el discurs de les autoritats educatives arreu del nostre territori, i que ha estat curosament repetida en els mitjans de comunicació. Certament, l'escola pública catalana presenta desigualtats importants. Els alumnes amb un entorn familiar més vulnerable, amb unes condiciones socioeconòmiques més delicades, pot ser que tinguin un ventall inferior de possibilitats d'aprenentatge en època de confinament (i també quan no hi ha confinament, convindria aclarir). Insisteixo en la idea que pot ser que tinguin: no es tracta d'una certesa absoluta, ni per tant una sentència condemnatòria. Penso que hem d'evitar veure les persones vulnerables o en una situació d'opressió com víctimes. Per tant, hem escoltat com el discurs públic sobre educació ha girat al voltant d'aquests temes les darreres setmanes i mesos: connectivitat, control de les desigualtats, no perjudicar als alumnes durant la tercera avaluació.

No obstant, una manera de posar-hi remei hagués estat una resposta ràpida de l'administració per posar equips informàtics i paquets de dades a disposició de les famílies més vulnerables, que no disposen d'Internet o d'un ordinador a disposició dels fills en el domicili on conviuen. Ara bé, abans de parlar de com ha estat la resposta de les administracions públiques, siguin les de govern central, l'autonòmic o fins i tot a nivell municipal, faré un aclariment que considero necessari: parlar només de connectivitat i enginys tecnològics per parlar d'educació és desviar el tema d'allò que és realment important. La qüestió no és simplement si hi ha maquinari per a tothom, sinó proposar als alumnes 
tasques -diferents propostes- que els convidin a aprendre. Per aprendre no és indispensable la tecnologia, però ens han conduït a pensar a tots nosaltres que sense tecnologia al seu abast, aquests infants i joves -especialment aquells que viuen en famílies vulnerables- estan totalment deixats de la mà de Déu, condemnats irremeiablement a l'ostracisme. I no és ben bé així. La dissort no es redueix a unes fràgils condicions de vida material, encara que no podem obviar aquest aspecte.

La tecnologia és un mitjà, una eina al nostre abast. No obstant, ja fa temps que hem pres la tecnologia com un objectiu. L'objectiu de les administracions és dotar de tecnologia als alumnes, fins i tot vendre determinat maquinari (recordem el criticat Programa $1 \times 1$ i els polèmics contractes de l'administració pública amb els fabricants informàtics). El mantra que en ocasions circula és que la tecnologia és educativa per se, o bé que l'objectiu de l'educació és que els alumnes aprenguin a fer funcionar segons quins dispositius, segons quin programari. Així es com es perd de vista la missió educativa de l'escola.

Quan el punt de partida és que els alumnes estiguin connectats, i no s'aconsegueix anar més enllà en repetir una i altra vegada que no es pot deixar a ningú sense connexió, sense maquinari, perdem de vista l'aspecte fonamental d'aprendre, que és una relació personal, íntima amb les tasques que ens permeten aprendre. Aprendre és pensar, conèixer, reflexionar. És clar que si tenim equips informàtics i connexions a Internet per a tots els alumnes a Catalunya l'experiència formativa que podran tenir serà millor, especialment quan no poden anar a l'escola o a l'institut. Podran tenir al seu abast un gruix important de materials, experiències, recursos, comunicació freqüent amb diferents especialistes d'àrea i amb els companys. Però si es dona el cas que els alumnes no poden connectar-se (no tenen Internet a casa, ni dades al seu mòbil), o no tenen un equip amb un processador o una pantalla suficientment gran per fer la feina en condicions, no vol dir necessàriament que no puguin aprendre durant aquests mesos, que no puguin treballar, que no puguin seguir aprenent des de casa seva.

Vull subratllar el següent: ens han insistit per tots els fronts -els mitjans de comunicació són còmplices de l'administració educativa en aquesta retòrica persistent- que tot es centra en la qüestió de si els alumnes tenen accés a Internet i a un equip informàtic en mínimes condicions. Però del que estem parlant és de subratllar la importància d'un altre assumpte. O bé també podem dir: estic plantejant redirigir el focus de la idea que allò que és important és la instància tecnològica (idea aplaudida per les administracions) cap a la instància del pensament i de l'aprenentatge de l'alumne, que és on pedagògicament penso que hem de posar l'accent.

Hi ha una lectura molt indicada que pot servir-nos per contextualitzar la persistent febre a favor de la tecnologia. Neil Postman va publicar en anglès, l'any 1992, el llibre Tecnópolis: La rendición de la cultura a la tecnología (Postman, 2018). Uns anys abans concretament l'any 1985- havia publicat Divertim-nos fins a morir (Postman, 1990), un altre llibre que convé destacar quan parlem d'educació i societat. Del seu Tecnópolis, volem destacar el següent fragment, que pensem que casa perfectament amb les reflexions que estem fent sobre la tecnologia en educació: «Las escuelas se dedican a enseñarles a sus hijos cómo operar con sistemas informáticos en vez de enseñarles cosas que serían más valiosas para ellos. En una palabra: los perdedores no obtienen prácticamente nada de lo que necesitan, y precisamente por eso son los perdedores» (Postman, 2018, p. 28). 
Per la meva experiència a l'institut on treballo, alumnes amb escassa connectivitat i sense ordinador han estat entregant les feines i, en nombrosos casos, fent molt bona feina. I d'altres, amb connexió i equip a ple rendiment, han fet així mateix molt bona feina. Per tant, en el final de curs 2019-20 m'he fet un fart de felicitar als alumnes per feines exquisides. Aleshores, estic ben segur que l'assumpte que estem tractant és un de ben diferent, i que es correspon bastant ajustadament a la següent reflexió: «La puerta a que el nivel de exigencia de los centros descienda, en el intento por adaptarse a cada alumno ante cada pequeña dificultad, está abierta» (Ruiz Paz, 2000, p. 127-128). Si decidim ficar dins del mateix sac a tots els alumnes escolaritzats en el moment que alguns d'ells en particular poden tenir dificultats, s'obre aquesta porta a que es baixi el nivell d'exigència per a tothom.

Un aspecte del confinament és que les seves condicions han deixat de costat els aspectes socials, la mediació física a l'escola, i ha posat en el centre la qüestió de l'aprenentatge, de la relació personal de l'alumne amb la tasca encomanada. Sense voler descuidar la dimensió corporal, ja que soc professor de l'àrea d'Educació Física, aquest és un fet que ha esdevingut molt destacable en l'experiència dels alumnes. Les setmanes de confinament els professors hem estat vivint de prop com els alumnes treballen d'una manera parsimoniosa, cuidant els detalls, fent feina: molta i molt bona feina. De fet, puc dir que altres col-legues professionals -i no parlo només de l'àmbit pedagògic sinó també de l'àmbit de la salut mental ${ }^{2}-m^{\prime}$ han corroborat aquesta mateixa impressió: aquests darrers mesos pacients i usuaris han estat fent una feina excepcional, treballant més i tot que el que treballaven abans del confinament.

Al costat d'aquest goig de veure la gent treballant i dedicant-se a la tasca, també puc dir que hi ha hagut alumnes amb ple accés a Internet, amb un ordinador completament a la seva disposició (o bé a compartir amb un germà o germana), i que pràcticament no han entregat cap feina en set setmanes. Són alumnes que tenen les condicions materials per poder treballar, i encara i així no treballen en les feines escolars. Aquest altre exemple ens mostra com no n'hi ha prou amb tenir el maquinari i l'accés a Internet assegurats. Cal, sobretot, tenir ganes d'aprendre, de treballar, d'emocionar-se amb les tasques que els professors estem plantejant-los. Així, no podem dir que tenir les condicions materials sigui sinònim de treballar: segur que tots els mestres i professors tenim un nombre important de casos que ens venen a la ment, dels alumnes que hem tingut durant aquest curs 2019-20, que s'han pres aquestes setmanes de confinament durant la tercera avaluació com un avançament de les vacances d'estiu.

Les condicions materials per aprendre són importants, i condicionen la possibilitat d'aprendre. Però no podem dir que tenir unes condicions materials més pobres o rudimentàries signifiqui necessàriament no poder aprendre, que és el que ha vingut a dir-nos els governs, les administracions públiques, els mitjans de comunicació. Hi ha infinitat de possibilitats a l'abast. Amb una televisió, amb un llibre, amb una revista. Sense Internet i sense ordinador es poden fer redaccions, resums, cròniques, càlcul, audicions de música, dibuixos i il.lustracions, improvisacions teatrals, exercici físic, jocs. Per tant, el món no s'acaba si no tenim accés a Internet. Ara bé, un cop feta aquesta reflexió, hem de tenir clar que la resposta de les administracions no ha sigut precisament ràpida per tal d'assortir a

(2) Vull agrair a les meves companyes terapeutes i psicòlogues de l'Associació Societat Científica Metaescrits que hagin compartit amb mi aquesta valuosa i bonica descoberta: com la gent a Catalunya ha estat treballant, pensant, aprenent des de casa durant el temps del confinament. 
les famílies més vulnerables de maquinari adequat, de paquets de dades que se'ls va prometre. S'havia posat el llistó del que s'havia d'aconseguir en el fet de facilitar connectivitat i maquinari per a tothom.

Des del primer dia en què els escolars de Catalunya van deixar d'anar a les escoles i instituts, que va ser el 13 de març de 2020, han hagut de passar en molts casos entre 6, 8 i fins i tot més setmanes fins que els ha arribat allò que els havia de permetre no perdre el fil del curs durant la tercera avaluació, i que sobretot no augmentessin les desigualtats educatives. Per tant, podem dir que la resposta institucional ha estat molt lluny de ser reeixida. El que hauria d'haver-se solucionat en 2 o 3 setmanes, ha necessitat el doble, o fins i tot el triple de temps. Aleshores, com podia l'administració pública complir amb el mandat que anava a garantir els drets dels més desafavorits? Com podia certificar que no augmentaven les desigualtats respecte els que obtenen millors resultats acadèmics? Ras i curt, i vist que no hi havia una decisió clara, inequívoca dels representants polítics ni de l'administració de fer arribar ràpidament les famílies vulnerables una connexió i un equip informàtic satisfactoris, bé s'havia de preveure una altra manera que «no augmentessin les desigualtats educatives». Aquest mantra políticament correcte -avui ben habitual dins del món educatiu- és fruit de la ja gairebé reglamentària mentalitat coaching, una mentalitat instal.lada primer a l'empresa i que ha arrelat també a les escoles (Pérez Gordillo, 2019). La «solidària» postura del govern havia estat plantejada. Ara calia veure si aquelles bones paraules enllaçaven amb unes satisfactòries condicions materials per aprendre.

La solució que es va trobar per fer complir aquest mantra en relació a que «no augmentessin les desigualtats educatives» durant el confinament va ser demanar al professorat que tingués ben present que l'avaluació no podia perjudicar els alumnes. La feina realitzada en aquestes 7 o 8 setmanes dins de la tercera avaluació -que començava a comptar a partir de després de Setmana Santa, però que les tres setmanes posteriors al 13 de març van ser un temps inèdit en el sistema educatiu, ja que no formaven part ni de la segona ni de la tercera avaluació- havia de servir per mantenir la nota prèvia, o bé pujar-la. Les indicacions del Departament del 21 d'abril eren prou clares: «En cap cas les qualificacions de la tercera avaluació podran modificar negativament l'avaluació dels aprenentatges aconseguits entre el setembre del $2019 \mathrm{i}$ el març del 2020» ${ }^{3}$. Aquest era el dictat de Departament, un plantejament que per molts docents implicava la necessitat d'escatir què és el que vol dir exactament aquesta indicació. Tanmateix, preguntar-nos per la «traducció» d'això és donar un pas més en la direcció d'esbrinar què està en joc en tot plegat.

Un cop esbossades aquestes condicions generals sobre l'aprenentatge en temps de confinament, així com les mesures i decisions del govern i l'administració pública, anem a mirar més de prop un cas particular d'avaluació durant el confinament: l'avaluació a I'ESO en un centre educatiu públic de secundària a Catalunya.

(3) Text extret del document «Instruccions per al desenvolupament de l'acció educativa i l'avaluació en el tercer trimestre dels alumnes en els centres on s'imparteixen els ensenyaments del segon cicle d'educació infantil, primària, secundària obligatòria i batxillerat davant la prolongació del període de confinament pel Covid19». Disponible a: https://govern.cat/govern/docs/2020/04/21/09/06/57f2559d-a20d-4d9e-bd54dce658448609.pdf Una notícia sobre aquest assumpte a El País (edició catalana): https://cat.elpais.com/cat/2020/04/21/cultura/1587482295_298683.html 11.6.2020 


\section{L'avaluació a un institut de secundària en temps de confinament}

Alguns centres educatius, fins i tot abans de la publicació d'aquestes instruccions del Departament d'Ensenyament del 21 d'abril, van avançar-se als esdeveniments i, potser per tal d'evitar possibles reclamacions de les famílies al mes de juny, van decidir curar-se en salut. La idea estava en la línia dels rumors que havien circulat als mitjans de comunicació sobre «l'aprovat general», una idea estúpida -però molt potent- que preparava el terreny per rebre amb els braços oberts l'enverinada idea que «els alumnes no poden suspendre». Una idea tant estúpida, de fet, com podem dir que és estúpida la ignorància que aquesta mena de pensament promou en l'alumnat i, de retruc, també en el professorat, que no només exigeix menys dels alumnes, sinó que també acaba per exigir-se menys a si mateixos. Per tant, l'horitzó és que s'estava aplanant el terreny per així els alumnes estiguessin aprovats a final de curs fent ben poca cosa.

En el cas del centre de secundària on treballo, la formulació adoptada era que els alumnes haurien d'obtenir almenys un Assoliment Satisfactori durant la tercera avaluació si es donaven algunes circumstàncies, algunes evidències. Una de les dimensions que més vull emfatitzar és que primer es va parlar informalment sobre aquesta idea: $a$ partir d'un mínim de tasques presentades del total d'encarregades, l'alumne podrà aconseguir l'Assoliment Satisfactori. En una versió posterior d'aquest criteri d'avaluació/qualificació, ja acostant-nos a un grau més alt de formalitat, no era necessari presentar cap tasca per aconseguir aquesta qualificació: es fixava la consideració d'entregar alguna de les tasques encomanades, o bé haver-se posat en contacte amb el professor (per videoconferència en les cites regulars, per correu electrònic... d'alguna manera). El redactat que es va oficialitzar amb anterioritat a la preavaluació va ser:

Aclariment: els alumnes que hagin presentat alguna tasca parteixen d'un 5 (Assoliment Satisfactori). Els alumnes que no hagin presentat CAP tasca ni hagin establert cap contacte amb el/la professor/a se'ls posarà No avaluat. En cap cas es posarà No assolit.

Al meu entendre, en aquest plantejament es confonia la realització i enviament de les tasques (l'alumne fent la feina) amb la consideració de posar-se en contacte l'alumne amb el professor (la comunicació). Si bé és cert que en un primer moment es planteja l'entrega d'alguna tasca per arribar a l'Assoliment Satisfactori, la següent frase estableix que l'alumne que no ha entregat cap tasca ni ha fet cap contacte amb el professor/a, li correspon No Avaluat (també li podem dir: No Avaluable). Per tant, podem entendre que algú que no ha entregat tasques però sí que s'ha connectat, podria esquivar el No Avaluat i enfilar-se fins l'Assoliment Satisfactori. Aleshores, tenint en compte les particulars circumstàncies del confinament que hem viscut, es podia arribar a despendre de les indicacions del centre que $n$ 'hi havia suficient amb fer algun contacte esporàdic amb el professor per haver d'atorgar almenys un Assoliment Satisfactori a l'alumne/a en qüestió.

Aquest tipus de confusió no és gens infreqüent. Ho he vist abans en la lògica que caracteritza la idea de participació de l'alumne a classe: si un alumne parla i enraona a classe seguint el fil del que s'està explicat, és que participa. No obstant si està callat, si està pensant, si està escoltant... aleshores no es considera -per termes generals- que està participant de la classe. Aquesta reflexió s'havia forjat en la preparació d'un seminari per commemorar el 40è aniversari de la mort de Gregory Bateson que va tenir lloc el passat mes de febrer (Valenciano, 2020), encara que la idea originalment havia estat desenvolupada en l'anàlisi conceptual de les categories 'jugar' i 'participar' en el reglament de minibàsquet (Valenciano, 2019). 
Una altra visita a aquest espai confús de la participació, segons com es categoritzi, I'he trobada recentment en un TFG dels qual he estat membre del tribunal d'avaluació. Concretament, l'autor del treball plantejava que en una formació per un col-lectiu determinat, el registre de l'assistència a les sessions es prendria com a element per a l'avaluació dels alumnes del curs. En aquest cas la confusió podia ser figurar-se que assistir era el mateix que estar interessat (quan de fet es pot assistir a l'activitat sense gaire interès, per obligació, per seduir al docent, etc.) i no assistir era idèntic a no estar interessat (encara que algú es pot arribar a perdre una sessió d'una formació, i estar més interessat que algú que hagi assistit a totes i cadascuna de les sessions).

Tornem, després d'aquest breu excurs, al que estàvem veient sobre l'avaluació a un centre de secundària. Hi ha un altre element a tenir en consideració: pel fet de retirar l'opció del No Assoliment del ventall de possibilitats en l'avaluació de l'alumnat durant la tercera avaluació, l'alternativa a no aprovar a tothom era ficar els alumnes menys treballadors (o amb els que no s'havia pogut contactar de cap de les maneres) dins de la gasosa categoria del No Avaluat, o No Avaluable. I afegim a aquest càlcul un altre factor més, que és preguntar-nos què passa quan a més a més del que ja hem esbossat, també s'introdueix una preavaluació - un tràmit institucional que genera una considerable dedicació dins de I'horari docent- en la tercera avaluació durant el confinament.

Aquesta pràctica de la preavaluació era normativa en el primer trimestre de 1er i 4rt de l'ESO fins fa dos cursos, i en la resta de cursos era discrecional de cada centre. Ara ja forma part de la normativa per a tots els cursos de l'ESO (Agraeixo al meu col-lega professional Eduard Hernàndez haver-me facilitat aquesta informació). En el centre en el qual treballo, es va establir aquesta preavaluació de la tercera avaluació, ja que donades les especials condicions que estàvem vivint es va pensar des de l'equip directiu que s'havia de donar una orientació respecte els resultats acadèmics dels alumnes a les famílies abans del final de l'avaluació. Fruit de la combinació de les instruccions per baixar el ritme de treball i/o flexibilitzar l'exigència acadèmica amb un altre factor, i de presentar a les famílies una preavaluació que per alguns professors semblava de fireta, aquesta confluència va fer despertar entre els meus companys de claustre (i jo mateix) la sensació de viure una situació molt contradictòria. Una companya professora va dir en una d'aquestes reunions de preavaluació: «estem mentint a les famílies». Més clar impossible. I penso que la manera com ens estàvem posicionant institucionalment envers la realitat educativa en el centre bé podia haver-se resumit, sintetitzat amb la següent frase: quan els fets ja no compten.

Aquesta sensació d'enuig individual, i també col-lectiu (l'esperit de grup entre el professorat és quelcom que es pot diluir en temps de teletreball, car i que durant aquest episodi que relato va florir una bonica sensació d'unitat professional), porta al meu entendre a veure la professió docent en clau ètica. En aquest moment en què la meva companya de claustre parlava en termes tan gruixuts com «estem mentint a les famílies», o bé jo feia servir la ja gastada imatge que els professors «ens estem fent trampes al solitari», aquest crit podia interpretar-se clarament en clau de voler revisar el nostre funcionament institucional. Jo va ser així com ho vaig entendre, i m'ho vaig prendre com un aspecte saludable del funcionament del claustre. El seguit de directrius de centre, així com les pròpies indicacions del Departament d'Ensenyament, ens estaven portant cap a una carreró sense sortida que cada cop era més evident. 
Davant l'absurd de la situació, el que ens quedava al professorat era poder mostrar la paradoxa d'una avaluació que defugia complir la missió facultativa d'avaluar. La norma establerta per la tercera avaluació semblava enfocar-se al propòsit de no mesurar ajustadament els resultats i mèrits acadèmics. Si mesurar és un dels elements consubstancials de l'avaluació (encara que no l'únic, sobretot des de les posicions innovacionistes ${ }^{4}$ ), en aquest cas la decisió es fixava en la següent línia d'acció: esquivar fer una mesura realista i ajustada dels resultats acadèmics dels alumnes del centre.

Tornem, no obstant, a un punt que hem tocat i del qual voldria comentar algun aspecte més. Em refereixo a la confusió entre la categorització de No Assoliment i No Avaluable. En eixamplar els marges per fer entrar els més clars candidats al No Assoliment en aquesta categoria del No Avaluable, trobo que els docents ens estàvem tirant pedres a la nostra pròpia teulada de diferents maneres:

1. Acceptant posar No Avaluable, estàvem expressant de manera oberta -ens donéssim més o menys compte d'això- que no havíem estat capaços de recollir suficients evidències per avaluar aquells alumnes que entraven dins de la categoria o condició de No Avaluables, i per tant estàvem reconeixent que no havíem fet la nostra feina, que qui havia fallat havíem estat nosaltres;

2. Falsejàvem l'avaluació en fer caure aquells alumnes que normalment es situarien del costat del No Assoliment en una altra categoria, una categoria No Avaluable així artificialment inflada;

3. També estàvem demorant allò inevitable, que és enfrontar el tràmit d'introduir les qualificacions al programa Esfera. Es dona el cas que Esfera no recull com opció del desplegable dins del seu programari considerar un alumne No Avaluable en els moments de l'Avaluació Final Ordinària i l'Extraordinària.

Aquesta fotografia avaluadora, «avaluativa»-evacuadora fins i tot podríem dir-que resulta falsejada (no apareixen qualificacions de No Assoliment en tots aquells casos en els quals hauria d'aparèixer) pot arribar a generar, com ja hem avançat més amunt, una imatge de falta de professionalitat del professorat. En alguns casos, a aquests professors forçats o convidats a aprovar a gairebé tothom, també se'ls suggereix que encara que hagin posat un Assoliment Satisfactori a un alumne que no ha entregat cap tasca en quatre setmanes (així era el cas en el moment de la preavaluació), sempre estàvem a temps de posar un comentari en el butlletí de notes. Això no fa sinó afegir una dimensió encara més increïble, mostrant amb molta claredat la incongruència entre les evidències que es fan servir per avaluar l'alumne/a, i el nivell d'assoliment que se li reconeix. Però com en el conte en el qual el rei va nu pensant que vesteix una roba fabulosa, s'acaba per veure la incongruència i, per tant, davant d'aquesta situació portada l'extrem ens podem adonar d'allò que no rutlla.

(4) Gregori Luri dedica unes delicioses pàgines a descriure què és el que ell entén per innovacionisme (Luri, 2019). En aquest treball dedicat a la imaginació conservadora, Luri presenta una visió crítica de la innovació -aquesta mirada és la mirada que duu a referir-se a aquesta innovació com innovacionisme- en la qual es destapa el rebuig de l'innovacionisme per la tradició (i per tant també per la transmissió cultural). Luri destaca com les persones que prenen una posició innovacionista s'aferren al que és nou com allò que és bo pel fet de ser nou, sense poder mantenir amb la tradició cultural aquell vincle d'admiració que la posició o mentalitat conservadora pot tenir. Hi ha una interessant i meticulosa ressenya del Ilibre de Luri (Ortega, 2020). 
Penso que no estem plantant cara a una única conseqüència negativa (el falsejament de les notes), sinó que aquesta situació generada en l'espai de la preavaluació apunta a l'explicitació de molts tics propis del sistema educatiu durant les darreres dècades. Per exemple, i com a mostra d'aquest exercici de desvetllament d'una realitat ja copsada abans dels temps del confinament pel COVID-19 en relació a les debilitats pròpies de l'avaluació, a un alumne imaginari li podria constar el següent al seu butlletí de notes de la preavaluació:

2on d'ESO A - PREAVALUACIÓ EN LA 3a AVALUACIÓ - CURS 2019-20

Alumne: Ramon Martorell

Matèria: Educació Física

Qualificació: Assoliment Satisfactori

Comentari: T'has connectat a 1 de les 4 videoconferències. Has entregat 0 de 4 tasques de la preavaluació.

Certament, hi ha un punt d'irònic -o directament: paradoxal- en la constatació de relació que s'estableix entre la qualificació i el comentari. Com podem arribar a dir que resulta «satisfactori» que l'alumne no hagi presentat cap de les tasques encarregades pel professor? Com pot resultar «satisfactori» que hagi fet acte de presència només en una de les quatre videoconferències que s'han dut a terme en l'assignatura? En reflectir aquesta paradoxa dels usos del sistema avaluador a secundària, podem veure també com s'explicita una qüestió que fa temps que diferents filòsofs i pedagogs estan subratllant. Ens recorda sàviament Javier Orrico (2016): «Nada más antidemocrático que ese pensamiento tan reaccionario de los progresistas de que lo importante es que todos los alumnos accedan a lo mismo y no que todos los alumnos accedan a lo mejor» (p. 188). Això que diu Orrico ho podríem aplicar també a la consideració dogmàtica que allò important era que tots els alumnes durant el confinament tinguessin connectivitat i maquinari.

L'avaluació que es posa en pràctica en aquests temps de confinament, al meu entendre, reflecteix les febleses que arrossega el sistema educatiu. De manera anàloga al sistema de control de danys (damage control) ${ }^{5}$ dins d'un vaixell o d'un submarí, algunes de les evidències relatades més amunt indiquen quins són els danys del sistema educatiu. I quan mirem com està el casc del vaixell que anomenem escola (o institut), se'ns mostra tota la cruesa de les seves febleses i debilitats. Sabem, aleshores, que el vaixell que és la institució escolar té forats al seu casc. No obstant, benauradament els professors de vegades pensem que això no impedeix seguir navegant, seguir remant, i no defallim. Ara bé, arriba un moment que ens donem compte de la dimensió del forat en el casc, i tota l'aigua que està entrant. Tanta aigua que estem cada cop més prop d'enfonsar-nos.

Penso que en aquesta tercera avaluació del curs 2019-20, el professorat en els centres de secundària hem descobert la dimensió d'aquest forat per on entra aigua en el vaixell. En els exemples que he anat introduint he tractat de mostrar algunes de les conseqüències del funcionament del sistema educatiu. Per mirar de complementar aquestes estampes que he anat presentant en el text, a continuació faré un recull de lectures, a mode de

(5) Segons la traducció de l'entrada en anglès de la Viquipèdia: «A les indústries marítimes, el control de danys és el control d'emergència de situacions que poden provocar l'enfonsament d'una embarcació d'aigua. Alguns exemples són: trencament d'una canonada o casc dins de la línia de flotació i danys a terra o amarraments durs contra un moll.» Disponible a: https://g.co/kgs/7obNxo [consultat: 11.6.2020]. 
passeig, en relació especialment a les més recents crítiques publicades sobre les institucions educatives contemporànies.

\section{Un passeig per les aules (breu selecció de lectures sobre els mals de l'escola contemporània)}

En aquest apartat del text vull recollir algunes aportacions plantejades per autors que han analitzat la vida a les aules. Començaré parlant d'alguns llibres de l'àmbit internacional, a continuació endreçaré les referències relatives a alguns autors que treballen i reflexionen dins de l'àmbit de les institucions educatives catalanes i espanyoles. A excepció d'un parell o tres de les primeres referències que documentaré, tota la resta d'obres seran publicacions que han aparegut entre els anys 2000 i 2020.

Seria gairebé sacríleg no anomenar en aquesta secció Mal d'escola (Pennac, 2008), un text que va tenir una gran acceptació entre la comunitat de professors. Pennac explica com una infància amb una deplorable experiència escolar no li ha impedit exercir d'adult de professor, i arribar també a ser un escriptor de reconegut prestigi. També seria inoportú deixar de banda, si precisament parlem de la vida a les aules, el clàssic text La vida en la aulas (Jackson, 1992). Aquests dos textos són segurament dues referències en diferents estils literaris, però que totes dues formen part d'un cert cànon contemporani eclèctic- en l'estudi i la reflexió sobre la vida a les aules.

Un text que es perfila com necessari dins del context en que tot això ha estat pensat i escrit és el llibre Los charlatanes de la nueva pedagogía (Morin, 1975). Aquest Morin -no confondre'l amb Edgar Morin- planteja algunes qüestions molt punyents, que de seguida veurem que conformen l'horitzó propi o teló de fons del discurs que hem anat recollint i ampliant durant els darrers anys. Comenta Lucien Morin: «Puesto que la opinionitis se alimenta sobre todo de la neofilia -amor de lo nuevo por ser nuevo-, es seguramente en la pedagogía donde sus consecuencias se manifiestan de manera más desastrosa» $(1975$, p. 11). Ara bé, a més a més d'aquest text d'antuvi, també paga la pena fer una referència més abans de seguir amb les referències internacionals.

Reconeguda abans la seva ascendència en el passatge dedicat a desvetllar certs aspectes de la inspiració primigènia d'aquestes reflexions, ara resulta pertinentment afegir quelcom més: que Enric Prats va entomar la reflexió al voltant d'aquest concepte d'opinionitis. Ho va fer per posar-li títol -o bé podríem dir també: per batejar, doncs al cap i a la fi escriure llibres és ben bé com tenir criatures, de les quals vius la seva gestació, les veus néixer, les presentes en societat... fins que arriben a independitzar-se dels seus productors biològics i simbòlics, i per tant els llibres que has escrit te'ls arribes a estimar com fills intel/lectuals - a una de les seves abundoses aportacions en el camp de la teoria de l'educació, concretament a Teorizando en educación: entre erudición, poesía y opinionitis (Prats, 2015). En aquest treball Prats distingeix entre tres posicions o models entre els que ens dediquem a la teoria de l'educació: erudits, poètics i opinadors. Els que conreen la vessant de l'opinionitis són els que s'enduen el gruix de les seves crítiques.

A continuació -i després d'aquest interludi per anomenar alguns arguments al voltant dels opinadors i els seus crítics- vull comentar certs aspectes del text ¿Qué le está pasando a la Universidad? (Furedi, 2018). Es tracta d'una obra assagística en la qual aquest professor universitari de sociologia a diferents indrets analitza les tendències que estan imposant-se en les institucions d'educació superior dels països anglosaxons (sobretot a 
EUA i a Gran Bretanya, encara que també amb alguns exemples d'Austràlia i Nova Zelanda). Entre altres assumptes, Frank Furedi aborda la qüestió de l'autocensura dels acadèmics en funció d'allò que es considera políticament correcte, així com també els gestos de les pròpies institucions universitàries per respondre a les rebequeries de l'alumnat, sovint satisfent-los amb mesures infantilitzadores. Del mateix autor hi ha també un molt destacable altre treball, que porta per títol Wasted. Why Education Isn't Educating (Furedi, 2009). Com a mostra del tarannà d'aquest darrer text, presentem la següent cita: «Enlloc d'entomar explícitament com conduir una conversació intergeneracional, la societat ha volgut esquivar aquest assumpte buscant una solució en les tècniques motivacionals i l'expertesa pedagògica» [La traducció és meva] (Furedi, 2009, p. 5). Penso que aquesta idea connecta amb la crítica al coaching de la qual ja hem fet esment (Pérez Gordillo, 2019).

També en l'àmbit anglosaxó, ens sembla important referir-nos al Ilibre The False Promise of Global Learning. Why Education Needs Boundaries (Standish, 2012). En aquest text l'autor comenta: "Aquesta expansió de la visió "global" de "l'educació" només pot distreure als docents de la tasca d'educar als infants respecte com és el món» (p. 67) [La traducció és meva]. Aquest anunci que fa Standish ens ha de servir d'advertència sobre els perills de convocar l'educació global. Com aspecte afegit a destacar, vull apuntar que coincideix que els Ilibres de Furedi (2009) i Standish (2012) han estat publicats per una mateixa casa editorial.

Al costat d'aquestes dues mencions, considero que hi ha una altra referència fonamental, ineludible en l'àmbit internacional: el treball d'E.D. Hirsch (2012). Actualment professor universitari emèrit, Hirsch ha estat durant un bon grapat d'anys dirigint un projecte transversal a moltes escoles i instituts dels EUA, el projecte Core Knowledge. La seva visió sobre la importància dels coneixements dins del currículum queda reflectida en la següent cita: «No es exagerado decir que una actitud anti-conocimiento es el elemento fundamental de la visión del mundo de muchos reformadores y de los maestros» (Hirsch, p. 107). Gregorio Luri -un autor que referirem més endavant amb més detall- ha posat especial èmfasi en el seu darrer treball, on apareix la idea del «coneixement poderós» (Luri, 2020).

Un aspecte afegit que comenta Hirsch i que ens interessa anotar en relació al tema de l'avaluació és la següent reflexió:

\footnotetext{
Varios autores del siglo XIX, incluidos William Hazlitt y Alexis de Tocqueville, establecieron perspicaces asociaciones entre el igualitarismo de las revoluciones estadounidense y francesa y la fe panteísta en la divinidad de todos los seres humanos. Tocqueville llegó al extremo de afirmar que el panteísmo estaba implícito en la idea misma de igualdad universal y, por lo tanto, de la propia democracia. El fenómeno escolar que en la actualidad se suele denominar "inflación de calificaciones" es quizás una inevitable consecuencia del individualismo romántico (Hirsch, 2012, p. 173).
}

En l'àmbit de la universitat catalana, un autor que sobresurt amb la seva anàlisi a cavall entre l'autobiografia i l'assaig és Jordi Llovet (2011), amb un treball ric i fecund. Ben eloqüent és el següent fragment, en el que fa un diagnòstic devastador de la institució universitària durant els darrers temps.

L'esperit humanístic que encara posseïa la meva facultat [de Filosofia i Lletres] mentre vaig cursar la carrera va quedar desintegrat i urbanísticament disgregat a la ciutat, de manera que, des de llavors fins a dia d'avui, hem hagut de veure, cada cop més, con un estudiant de Dante no sap gaire res de Virgili, un estudiant de filosofia aristotèlica no sap llengua grega, un estudiant d'Història d'Amèrica no sap res de Melville, un estudiant de Shakespeare no coneix el regnat de la reina Elisabet, un estudiant de filologia espanyola no ha llegit Carles Riba i els estudiants de pedagogia o de psicologia no saben -i ho he 
escrit a posta amb lletra cursiva, per què una cosa és dominar estratègies i una altra cosa és saber-res de res. (Llovet, 2011, p. 26).

Un altre autor que paga la pena destacar és Gregorio Salvador (2004). Ell aborda tant els efectes de les reformes educatives en l'educació obligatòria, com també la qüestió de la crisi institucional de la universitat. Mirem de ben a la vora aquesta segona qüestió: «el descabezamiento de la Universidad se cumplió sin reservas y mi cabeza cayó al cesto con las de todos los demás. Afortunadamente para mí, yo la tenía ya trasplantada a otro cuerpo, a otro ámbito menos vulnerable y manejable, y eso me ha permitido, entre otras cosas, escribir estos artículos que ahora reúno y contar y juzgar, desde una cierta distancia, las cosas que iban ocurriendo en lo que había sido mi mundo» (Salvador, 2004, p. 23). I respecte la vida als centres educatius exposa el següent: «Porque de una enseñanza desnortada y sin verdaderas exigencias, igualada a la baja, horra de contenidos, donde todos pasan y todo vale, lo único que se puede obtener, y efectivamente se ha obtenido, es una mala educación. Y ese logro sí está bien a la vista nada más cruzar las puertas de la mayor parte de los centros docentes. Por ahí, por la didáctica de los comportamientos, podrían empezar la recuperación de las humanidades» (Salvador, 2004, p. 84).

Si ens acostem a la realitat de les aules catalanes, una recent i interessant aportació és que la que ha publicat el professor de literatura a secundària Andreu Navarra (2019). Certament, aquest autor fa una lectura crítica de la vida als instituts catalans, amb observacions punyents i oportunes, com per exemple: «Un alumno que no acepta las reglas de su comunidad docente no aprenderá ni con cartillas de los años setenta ni a través de proyectos» (Navarra, 2019, p. 147). Aquesta frase és tota una declaració d'intencions enfront de tots aquells que s'ho juguen tot a la carta de la innovació pedagògica, del treball per projectes, de les noves tecnologies a les aules, de l'educació en valors, de l'educació emocional o del mindfulness. Navarra fa servir com bastida en la qual poder enfilar-se el pensament de Gregori Luri, un autor de referència en la crítica a alguns dels tics de la «nova educació».

Aquest darrer autor ha publicat un llibre que porta un eloqüent títol: La escuela no es un parque de atracciones (Luri, 2020). En les seves pàgines, Luri ens adverteix: «Buscando las nuevas formas de aprender, parece olvidarse de aquello a lo que debieran servir, los contenidos» (p. 27). I al costat de Luri, també volem anomenar Javier Orrico (2016) i Alberto Royo (2016). Triem aquestes dues seves obres, encara que han estat autors més prolífics. No obstant, per poder parlar de tots dos, convé aclarir que hi ha diferents precursors d'aquests dos (o tres) autors (si fiquem en el mateix sac a Luri, encara que no pertany a la mateixa generació que Orrico i Royo), l'obra dels quals comentarem de seguida.

Com precursors de les mirades particulars d'Orrico, Royo i Luri, parlarem de Mercedes Ruiz Paz i de Ricardo Moreno Castillo. Ruiz Paz, una autora que amb dos excel.lents llibres (Los límites de la educación, 2000; La secta pedagógica, 2003), no és una autora especialment anomenada en el camp de la pedagogia. Ella estableix un horitzó clar en relació als mals de l'escola espanyola:

\footnotetext{
Pero la secta comenzó a afear su tarea como enseñantes de los contenidos culturalmente valiosos y a poner en duda desde la utilidad dicha tarea hasta la oportunidad de los conocimientos mismos. Comenzó a desosegarlos, obligándoles a cuestionarse sin descanso la posibilidad de que estuvieran siendo malos docentes por dedicarse a enseñar, y de que su influencia sobre los alumnos estuviese resultando perjudicial. Comenzó a explotar su sentimiento de culpa. (Ruiz Paz, 2003, p. 19)
}

No pocos docentes comenzaron a sentirse responsables de los males de la enseñanza, culpa que ya se encargaban los pedagogos y sus allegados de reforzar y publicitar. (Ruiz Paz, 2003, p. 20) 
Ricardo Moreno Castillo, catedràtic de matemàtiques a secundària, l'any 2006 va publicar Panfleto antipedagógico, un text que en una versió preliminar ja feia algun temps que corria per la xarxa. Aquest autor mostra la seva contrarietat amb la situació educativa a mitjans de la dècada dels 2000. Arran d'aquest primer text, va seguir la seva obra amb tota una nissaga de treballs que segueixen l'estela del que hem citat més amunt (Moreno Castillo, 2008; 2016; 2019). Com a testimoni de la seva mirada crítica, deixem aquí una al.lusió dirigida cap alguns discursos benintencionats de l'educació en valors: «No está mal que se hable a los niños del día de la paz, y que lo celebren dibujando la paloma de Picasso, pero si al mismo tiempo no se les enseña a comportarse en los lugares públicos y a ceder el asiento a las personas mayores, se ha perdido el tiempo» (Moreno Castillo, 2006, p. 68).

Alberto Royo va tenir un fort impacte als mitjans de comunicació i en l'opinió pública l'any 2016. En el seu text Contra la nueva educación (Royo, 2016) articulava una crítica argumentada a segons quines propostes innovadores, a la idea de la rellevància del guru o expert en educació, destacant la importància que tenen els coneixements i la passió per la matèria, tant pel que fa a la feina del professor com també per l'aprenentatge dels alumnes. Per la seva banda Javier Orrico té un discurs semblant en el contingut a allò que planteja Royo (o també podem dir: Royo es sembla a Orrico en el que diu), i no obstant en les formes de dir-ho és ben diferent.

Orrico planteja una sèrie de crítiques punyents al sistema educatiu espanyol, i assenyala el paper clau dels pedagogs, dels polítics i de l'administració pública en el desgavell educatiu. Es reserva, a més a més, alguns altres dards enverinats dirigits al cos d'inspectors, i també al funcionament dels processos d'oposició. Ara bé, en les formes Orrico parla amb un to desenfadat i una adjectivació florida, ben diferent al llenguatge mesurat i sense estridència de Royo. Un fet destacable en la trajectòria intel.lectual de Javier Orrico és que la seva visió sobre el sistema educatiu se l'ha format en dues etapes com docent d'institut, i una etapa intermèdia (que va coincidir amb un parèntesi en la seva funció docent) en què va ser redactor de la secció d'educació de Diario 16 a Múrcia. Per tant, ha vist el que passa a l'educació espanyola des de diferents posicions privilegiades.

Així mateix, un altre autor que vull destacar és José Ramón Rodríguez Prada (2012). Se li pot reconèixer, sense dubtes, el seu ampli coneixement de les reformes educatives a partir de la dècada de 1980. Al seu treball Conflicto y reforma en la educación (1986-2010). Los años decisivos: de la rebelión estudiantil a las consecuencias de la LOGSE executa un delicat treball d'anàlisi, a cavall entre la història, la sociologia i la pedagogia. Presentem una de les seves reflexions:

\footnotetext{
Hasta entonces la labor del profesor era clara: enseñaba lo que sabía de acuerdo a un programa académico aprobado por el Ministerio de turno; ahora no se trataba de instruir al alumno sino de educarle, en el sentido de inculcarle ciertos valores. No era lo mismo. Hay una diferencia sustancial. Cuando un docente enseña trata que el alumno aprenda una serie de contenidos conceptuales o instrumentales relacionado con un saber específico; pero la Reforma intentaba algo más: modificar la conducta del alumno, orientándola en determinada dirección, naturalmente loable y hasta deseable para el legislador, pero no para el profesor, que se ve a sí mismo como un mero transmisor de doctrinas, valores y opiniones acordes con unos prejuicios de no se sabe quiénes, y en ocasiones contrarias a las suyas. (Rodríguez Prada, 2012, p. 87)
}

També vull anomenar un llibre ben recent de José Sánchez Tortosa (2019), corresponent a la publicació del seu treball de tesi doctoral. Per una banda aquest autor ens ad- 
verteix: «Ese afán ingenuo por ser democráticos con los estudiantes conduce a introducirlos demasiado pronto en los consejos escolares, implicarlos en su educación con una participación para la que aún no están preparados en la mayoría de los casos, invitarlos a elegir entre asignaturas de las que lo desconocen prácticamente todo (esa especie de educación a la carta)» (Sánchez Tortosa, 2019, p. 84). A més a més, segons aquest autor també podem considerar que

\begin{abstract}
[e]l alumno sólo puede aprender, y dejar de ser alumno, si parte de una posición de inferioridad técnica, garantizada institucionalmente por medio de la aplicación rigurosa y coherente de las normas de comportamiento dentro de un centro escolar, con respecto al que enseña. Sin jerarquía escolar, bajo el igualitarismo posmoderno, ese populismo pedagógico que pretende que el alumno y profesor sean iguales (el profesor sería La Casta, el alumno, La Gente), el sujeto es más propenso a aferrarse a los nudos que forjan su identidad (afectivos, morales, psicológicos...) y, seguro en esa ceguera, más predispuesto a negarse a aceptar la autoridad de alguien en quien no ve superioridad alguna. (Sánchez Tortosa, 2019, p. 54)
\end{abstract}

De manera anàloga a la reflexió sobre que el text d'Alex Standish (2012) i de Frank Furedi (2009) estaven publicats per la mateixa casa editora, penso que també correspon subratllar que els Ilibres de Sánchez Tortosa (2019) i Pérez Gordillo (2019) han estat publicats per la mateixa editorial. I no només això, sinó que formen part d'una mateixa col-lecció: corresponen al primer i segon llibres de la col-lecció Akal Educación. Per acabar de posar les cartes sobre la taula, penso que és interessant afegir que els directors de la col·lecció (Enrique Galindo Fernández i Olga García Fernández) tenen una destacable publicació que lliga amb els temes que hem estat tocant, amb un especial accent en la crítica al neoliberalisme en l'educació (Fernández, García i Galindo, 2017). I no resulta una qüestió que puguem obviar, que no tots aquests autors fan una aproximació crítica a la situació de l'escola i de l'educació des de les mateixes posicions ideològiques. Trobem en els casos dels autors i també dels directors de la col-lecció Akal Educación- diverses posicions ideològiques, la qual cosa penso que és d'agrair en un mercat editorial que cada cop més tendeix envers una polarització de les publicacions més pel biaix ideològic que per la qualitat intel.lectual de l'obra.

Dit això, i en les antípodes del to majoritàriament acadèmic del text de Sánchez Tortosa, una última menció respecte un autor fora pistes abans d'iniciar els comentaris finals. Aquesta denominació -fora pistes- ha estat triada d'acord a la via de difusió del seu text, que és l'autoedició. Potser Pablo López Gómez (2018) amb el seu text Lo que estamos construyendo no ha entrat als circuits més reconeguts i prestigiosos del discurs crític dels docents, i no obstant això planteja valuosos aspectes que convé escoltar i prendre nota. Una de les reflexions que ja hem vist en d'altres autors, i en la qual ell insisteix és: «No podría ser de otra forma: nuestro sistema actual anima tanto a no estudiar que, al final, muchos alumnos no están dispuesto ni siquiera a estudiar lo poco que se pide para aprobar de regalo» (p. 37). Així mateix, també vull destacar un altre fragment seu que pot servir-nos per resumir bona part del que hem glossat en aquest apartat:

Formuladas en este contexto, las de las propuestas de las neopedagogías insisten principalmente en estas tres líneas:

- $\quad$ Primera: la transmisión de conocimiento adquiere un papel muy vago y secundario en la educación, cuyos objetivos principales han pasado a ser los aspectos emocionales de la formación del alumno, la felicidad o el fomento de virtudes como la creatividad o el liderazgo.

- $\quad$ Segunda: los conocimientos adquiridos deben ser susceptibles de una aplicación práctica en la vida del alumno. 
- Tercera: la omnipresencia de Internet y la tecnología digital. Las nuevas tecnologías están sacralizadas. (p. 88)

Acabem així aquest passeig que ha servit per fixar posicions, i sobretot per il.lustrar alguns dels aspectes teòrics d'allò que he anat abordant amb anterioritat. Tot el que he presentat en les seccions anteriors - des d'una perspectiva viscuda en el rol professional docent, encara que sense defugir en cap cas els elements teòrics i reflexius pertinentsqueda ara ressituat per l'exercici d'establir una selecció - provisional- d'autors que serveixen al propòsit d'articular i situar el meu discurs crític. També desitjo que aquesta tria serveixi com una selecció de lectures que pugui ser suggeridora pel lector o la lectora, i que a més a més d'obrir la possibilitat a conèixer nous autors i punts de vista, pugui servir en un futur per elaborar una guia de lectura sobre els autors que han treballat el tema dels mals de l'escola contemporània (o bé els mals contemporanis de l'escola).

\section{Comentaris finals}

La figura de l'intel-lectual, del professor coneixedor del seu métier (treball, ofici), convoca també la idea del compromís ètic amb la seva feina. El professor és algú compromès amb una sèrie d'elements que el situen en el món, en la tradició cultural. Aquesta és, no obstant, una figura que ha anat perdent pistonada en les nostres societats: «por regla general, el profesor de filosofía que emprende tareas de las llamadas mediáticas pasará, más tarde o más temprano, a ocuparse en exclusiva de estas, y convertirá sus quehaceres académicos, en caso de que los mantenga, en una prolongación de la tertulia de televisión, con parecido nivel y propósito» (Valdecantos, 2014, p. 66). Certament, l'avançament de la tecnociència és un element que fomenta la destrucció d'aquesta figura del professor, com també del filòsof i de l'intel.lectual.

Al costat d'aquest vaticini, penso que és interessant recuperar allò que ens explicava José Carlos Bermejo sobre el paper que Edmund Husserl esperava que complissin els filòsofs i, per extensió -ens diu Bermejo-, també els intel-lectuals. Podem reconèixer un model de professor lliure, capaç de crear un pensament propi dins d'un determinat espai institucional i polític, que no s'identifica amb un activista polític, ni tampoc amb un redemptor messiànic. Així Husserl, que va ser un exponent d'aquest model de professor Iliure, va anomenar als filòsofs funcionaris de la humanitat, entenent que el funcionari és un representant del l'interès comú i del bé públic (Bermejo, 2009, p. 18-19). Tanmateix, en relació amb aquesta reflexió vull cridar l'atenció sobre el fet que els instituts s'estan confonent cada cop més amb els serveis socials: «Los servicios sociales de nuestra sociedad son los institutos, sin los equipos y personal adecuados para realizar esa función. La educación secundaria está dejando de ser educación para convertirse en un difuso servicio de retención y de ocio» (Navarra, 2019, p. 99). Això repercuteix inevitablement en la transmissió cultural, doncs el focus ja no es centra tant en els sabers i els coneixements que els alumnes puguin obtenir i conrear, gràcies a una docència centrada en els continguts i en la transmissió, sinó que es repeteix la importància de «l'acompanyament emocional», com hem sentit fins a la sacietat en els telenotícies aquests darrers quatre mesos. Aquesta tendència és el que en l'àmbit anglosaxó s'ha vingut a anomenar «therapeutic education» (Furedi, 2004; Mertanen i Brunila, 2017). Trobem, sortint de la llengua de Shakespeare, un interessant treball abordant aquest «gir terapèutic» en la cultura, concretament en l'article provinent de la Universitat de Sevilla (Gavira, 2012). 
Arrossegar la funció dels serveis socials fins l'escola i centrar-ho tot en «l'acompanyament emocional» són estratègies que comparteixen un tronc comú: la despolitització de l'educació. Per poder-se donar aquest gir social i de despolitització, apareix també una clamorosa -i necessària per què es doni aquest gir- desaparició de la filosofia en la nostra societat. Ho podem copsar en la següent reflexió sobre el pla d'estudis del Grau de Pedagogia:
Sembla oportú detallar que aquell pla d'estudis contemplava l'assignatura de Filosofia de l'Educació com a matèria obligatòria en el tercer curs de carrera, és a dir, en el primer d'especialitat després dels dos anys comuns dels estudis generals de Filosofia i Lletres, en què l'estudi de les qüestions filosòfiques tenia una presència ben significativa. Així, a primer curs, els i les alumnes de Pedagogia havien de seguir l'ensenyament de matèries comunes, com els Fonaments de Filosofia a primer curs, que es completava a segon amb la Història dels Sistemes Filosòfics, de manera que una persona llicenciada en Pedagogia seguia - com a mínim - tres cursos sencers de qüestions filosòfiques, repartits en cadascun dels tres primers cursos de carrera que es perllongava durant cinc cursos (Cercós i Brasó, 2019, p. 13).

Per tal que aquest gir social es pugui donar, Furedi (2018) ens parla de la inclinació de l'educació -a banda de deslligar-se progressivament de la filosofia- envers l'infantilisme. Lligat a aquest assumpte, també ens parla de la preocupació per com els continguts dels programes docents afecten la sensibilitat dels alumnes, sensibilitat que es pot veure ferida o tocada. Així queda palesada aquesta circumstància en la resposta respecte a un Treball de Final de Grau, en la qual l'alumna exposa als membres del Tribunal: «Espero haver-me explicat adequadament i amb claredat, ja que $\mathrm{m}^{\prime}$ ha costat encaixar una mica alguna pregunta». La idea d'encaixar, per un professional i un amateur de l'esport com jo, convoca necessàriament la imatge del boxejador que mira d'encaixar els cops del púgil adversari sense arribar a caure estabornit. Això, per tant, penso que apunta a la qualitat o la condició de la «duresa» de les preguntes tal com són percebudes per l'alumna. La duresa, és clar, de l'escomesa que l'alumna ha sentit que li plantejava el Tribunal amb les seves preguntes i observacions.

Al meu entendre, sembla que hi ha un rastre gairebé corporal que deixen les preguntes en aquesta alumna. Malgrat encaixar es pot interpretar de diferents maneres, una d'elles és encaixar el cops en un combat, bé sigui en un entrenament, bé en un combat oficial. Un altre ús freqüent de l'expressió «encaixar» correspon a la idea d'encaixar una mala notícia, com bé pugui ser la mort d'un familiar. Per arrodonir aquest exemple d'encaixar, penso que una altra manera de tractar aquesta categorització de la «duresa» de les preguntes, bé podria ser plantejar-ho com categoria anàloga a la idea d'exigència sobre la qual hem parlat al llarg del text. M'aventuro a dir que potser aquesta l'alumna necessitava enfortir-se més en el combat cos a cos (de nou sembla pertinent referir-se a «la dura vida enemiga»), en l'entrenament pugilístic que tant i tant apreciaven a l'antiga Grècia (Diem, 1966). O bé en algun equivalent contemporani a aquell entrenament i educació de la voluntat, de la perseverança. No debades trobem un dels treballs més pertinents en la sociologia contemporània tractant precisament l'experiència de l'autor com aprenent de boxador (Wacquant, 2004).

Tot i que penso que s'ha fet prevaldre «l'acompanyament emocional» molt per davant dels aspectes acadèmics en les institucions educatives, considero que la dimensió de l'autonomia de l'alumnat durant els mesos de confinament a la primavera de 2020 es pot haver desenvolupat amb escreix. Especialment això ha estat possible pel fet que abans he comentat que s'ha esborrat una part important del contacte social a l'escola. En els mesos que ha durat el confinament, l'alumne ha quedat a soles amb la tasca, refer- 
mant -o potser, en alguns casos, fins i tot inaugurant- una dimensió íntima de l'aprenentatge. D'aquesta manera i mentre ha durat el confinament, el que ha quedat al descobert ha sigut la tasca a realitzar.

Els alumnes s'han consagrat a fer feina aquests mesos, i queda constància en la qualitat de les tasques entregades. Així, doncs, és clar que alguns d'ells i elles han pogut desenvolupar la seva autonomia en el treball intel.lectual i material. No obstant, actualment segueix existint una certa noció de qui és autònom que potser encara té una petjada més forta a la nostra societat que no la imatge dels alumnes estudiant i aprenent a la seva cambra. Penso que pel damunt de l'estudiant autònom a soles amb la tasca preval la imatge del treballador autònom, l'empresari de si mateix, l'emprenedor. Parlem, és clar, d'aquesta figura mítica que es posa damunt d'un podi i, simultàniament, es continua l'obra engegada d'anar destruint l'Estat del Benestar i retallant els serveis públics: «El pequeño prestador de servicios autónomo, que se explota y depende totalmente de sí mismo, es el héroe futuro del trabajo, ya que no significa una carga para los balances ni reduce los beneficios, no necesita de una red social ni de protección, es un acróbata en la cuerda floja que, en caso de despeñarse, ha de ser metido en una bolsa para cadáveres y quitado de en medio» (Trojanow, 2018, p. 52). Cada cop és més clar i evident quins són els papers que se li reserva a les escoles, als instituts, a les universitats: «Ahora hacen falta emprendedores dispuestos a lo que sea para formarse voluntariamente a lo largo de toda la vida en lo que sea. La pedagogía, la psicopedagogía, el coaching, pueden ayudar mucho en ello. La filosofía, más bien, es un testigo muy molesto del desastre civilizatorio que todo ello supone» (Fernández, García i Galindo, 2017, p. 333).

Enfront aquesta estampa, cal deixar clar que l'avaluació dels joves estudiants és una qüestió d'interès públic. En aquests darrers mesos hem vist com li tibaven totes les costures a un sistema que ja fa temps es troba en situació precària o, més ben dit, precaritzada $^{6}$. El debilitament progressiu dels sistemes sanitaris i educatiu després de diferents onades neoliberals ha desembocat en aquest 2020 en un primer moment d' «emergència sanitària», i a continuació, un segon moment que ha estat referit com d' «emergència educativa». Els anys que portem sense suficient inversió en serveis públics, a la llarga, es deixen notar com durant aquests mesos de confinament. No és accidental que apareguin aquestes dues emergències en l'horitzó de la gestió de la res publica. Podem dir que ha aparegut ja fa temps un aspecte destacable de la realitat educativa, aspecte que no l'hem descobert recentment. Una descripció acurada d'aquesta situació estructural podria ser aquesta:

Aprendan o no, ya la ley establece que acaben pasando de cursos suspendan cuantas suspendan. Pero como eso, al parecer, no basta, aunque la ley no obliga a aprobar a nadie a quien ni sabe ni quiere saber, siempre se puede maniobrar y coaccionar al profesor para que incluso así se apruebe: la ley aquí no interviene, ergo no se opone.

Que los alumnos se vayan aprobados, se trata de eso. (Juanatey, 2015, p. 85)

En aquests darrers mesos ens hem vist abocats a reconèixer tota la magnitud de la tragèdia, un escenari preocupant ja anticipat abans. En aquestes condicions excepcionals

(6) De la mateixa manera que no és el mateix pensar en el subdesenvolupament del Tercer Món que en la idea del «desenvolupament del subdesenvolupament» (noció que han treballat autors com ara Walter Rodney $i$ Samir Amin), tampoc és el mateix pensar que el sistema educatiu és precari, que pensar que està precaritzat, com bé ho poden estar també el sistema sanitari i del mercat laboral en el seu conjunt. 
que s'ha hagut de posar per escrit segons quins criteris d'avaluació (i també d'altres assumptes de moltíssima rellevància, com a quines edats algú quedava fora de poder ser atès amb respirador als hospitals), ens hem trobat cara a cara amb la brutalitat del neoliberalisme. Ens hem donat compte de com l'Estat del Benestar en el que havíem pensat que estàvem vivint ha quedat reduït a les cendres.

Tornant sobre l'avaluació, i respecte aquest perllongat temps sense docència presencial, hem pogut arribar a topar-nos amb l'explicitació de l'exigència acadèmica segons uns criteris paupèrrims. A partir d'evidenciar això, aquesta operació ens permet parlar sense embuts, sense màscares- del que s'està ordenant fer als instituts amb l'avaluació de l'educació obligatòria. El fet de poder mirar la nuesa d'aquestes situacions que queden al descobert ens permet poder identificar-les, copsar-les sense cap mena de dubte. Desapareixen les distorsions, i tot queda al descobert. Per tant, entenem que malgrat els problemes i dificultats que ha dut la gestió del COVID-19, tanmateix es constitueix un element valuós: aquest desvetllament de la realitat existent en la mesura que ens mostra la tendència abans ja establerta i que ara ha quedat destapada, nua, completament clara i inequívoca?.

La qüestió de l'avaluació tal com l'he presentada estableix contacte amb la noció de veritat (recordem-nos: quan els fets ja no compten), i també amb la noció de justícia. Seguint el fil d'aquesta idea afegiré: «El relativismo posmoderno ha absolutizado la tolerancia, la ha convertido en el valor supremo de la democracia, cuando en realidad debe estar siempre gobernada por otra virtud superior, la justicia, que limita a su vez a la propia tolerancia» (Tejedor i Bonete, 2006, p. 15). En aquests nostres temps postmoderns, hem de tenir present un horitzó de virtuts que ens pugui guiar. I la tolerància que esdevé tolerantisme és un dels paranys més recurrents en la nostra societat, un biaix del qual el funcionament institucional de les escoles, els instituts i també les universitats no escapen.

Volem encarrilar la recta final de l'article amb la següent cita: «Si analizamos los discursos de diferentes gurús educativos de las últimas décadas, todos parecen converger en la afirmación de que los profesores son cómplices de un sistema escolar diseñado para acabar con la curiosidad natural de los niños, con su espontáneo amor al saber y, sobre todo, con su creatividad» (Luri, 2020, p. 53). Si bé és cert que és important que els alumnes puguin esdevenir creatius, no podem caure en el parany de pensar-nos i considerar-nos els docents com un obstacle pel desenvolupament de la seva creativitat. En tot cas, els docents podem plantejar segons quines constants -allò que en l'àmbit terapèutic es coneix com enquadrament- que permetin als alumnes situar-se enfront de la tasca a realitzar, enfront de l'aprenentatge.

Per una banda, tradicionalment dissenyar i cenyir-se a un pla d'avaluació és un dels elements fonamentals que configuren aquest espai simbòlic de la formació que dirigeix i regenta el docent. Per un altre costat, actualment demanar als professors que tots els alumnes han d'arribar a l'Assoliment Satisfactori representa gairebé dir-nos que no els

(7) Li agraeixo a la psicòloga Raquel Boquet, col·lega professional i membre de l'Associació Societat Científica Metaescrits, haver compartit aquesta idea durant la nostra reunió de treball del 7 de juny de 2020. 
avaluem $^{8}$. Una alternativa a aquesta possible interpretació, o potser millor dit, un complement per llegir aquest manament, seria veure que l'escala de notes ha passat del 0-10 al 5-10. Encara que ens I'haguem d'imaginar aquest 5-10-sobretot un cop es van prohibir les qualificacions numèriques-, penso que podem assajar aquesta aproximació. Fent un exercici d'imaginació, podem entendre aquesta idea de començar per l'Assoliment Satisfactori com una manera de fixar el següent criteri: que qui no ha fet brot tindrà Assoliment Satisfactori. A partir d'aquesta línia de sortida, els alumnes que hagin treballat i la qualitat de la seva feina hagi estat millor o pitjor, cadascú podrà enfilar-se fins l'Assoliment Notable i l'Assoliment Excel-lent. Llegir-ho d'aquesta segona forma (que del 0-10 hem passat al 5-10) ens permet plantejar-nos, així mateix, situar el que seria «estar suspès» o el No Assoliment dins de la franja o lloc que correspon a l'Assoliment Satisfactori. Per tant, l'Assoliment Satisfactori seria en aquest cas el nou indicador d'estar suspès, si el nostre rang de notes va del 5 al 10 i prou, sense «suspesos» per la via oficial.

Dit això, quan enlloc de cenyir-nos al pla d'avaluació de l'assignatura ens posem a negociar les condicions de la nostra rendició i ens afanyem a rebaixar l'exigència acadèmica, finalment -també irremeiablement- ens aboquem a «regalar la nota» a l'alumnat. En aquests tremolosos i tristos moments, els docents estem faltant a la nostra funció social de vetllar per un virtuós i saludable aprenentatge dels escolars. És una qüestió cabdal de l'ètica professional de cadascun dels docents preguntar-nos per les mentides que estem explicant a les famílies amb l'ajuda dels millors vestits del llenguatge pedagògic que ens proporcionen els polítics i l'administració educativa, així com també la còmplice direcció dels centres. Més que no apuntar exclusivament als docents com a còmplices de la crisi acadèmica i social -encara que de vegades ho som-, caldria atendre al funcionament institucional que ha quedat establert els darrers temps com hegemònic, i que les mesures amb la detecció del COVID-19 no ha fet sinó explicitar.

En darrer terme, per tant, es tracta de preguntar-nos per la dimensió ètica que resideix en la comunicació codificada que usem el professorat, especialment en el moment d'abordar l'assumpte central i innegociable de l'avaluació. Si bé sabem que l'avaluació no és l'únic important en els processos educatius, no podem pensar una educació virtuosa deslliurada de qualsevol rastre d'avaluació. Perquè avaluar serveix a l'alumnat per conèixer millor els seus resultats, fer els ajustaments necessaris, i poder així continuar i consolidar el seu procés d'aprenentatge.

\section{Un darrer apunt}

Inger Enkvist és una autora de reconegut prestigi acadèmic. Aquesta hispanista d'extensa trajectòria ha destacat en els darrers temps pel seu paper, força mediàtic, posant el crit d'alarma sobre l'estat crític de l'escola arreu. Un dels seus punts forts és l'anàlisi i comparació de sistemes educatius nacionals, doncs és bona coneixedora de les diferents realitats educatives. Fruit d'aquesta expertesa, una de les advertències que ha fet Enkvist en

(8) Li agraeixo a Eduard Hernàndez el comentari respecte quin missatge s'intueix en el fet que la direcció d'un centre d'ensenyament li demani als professors que els alumnes comencin a ser avaluats a partir de l'Assoliment Satisfactori. Aquesta va ser una idea que ell va compartir durant la sessió del Seminari «Lectura Confi(n)ada 2.0» que va celebrar-se el 13 de juliol de 2020 dins del cicle d'activitats de debat i reflexió abans anomenades, i organitzades pel GREPPS, com ja hem indicat. En aquella sessió vaig presentar els principals aspectes d'aquest text. 
aquests darrers anys ha estat la deriva de l'educació al seu país natal, Suècia, el qual segons ella tenia un molt bon sistema educatiu fins la dècada de 1960.

Amb les reformes introduïdes a partir d'aquella data, aquesta excel.lència del sistema educatiu suec ha anat deteriorant-se. Ara bé, també hem de tenir en compte el següent: «Suecia está rectificando por lo menos en parte su apuesta por la nueva pedagogía, mientras que Finlandia está gozando de un enorme prestigio por no haberlo introducido» (Enkvist, 2014, p. 48). Bé sigui Suècia, Finlàndia o Corea del Sud... tots aquests països són sovint posats com els exemples dels millors sistemes educatius dels món. Al mateix temps, constatem que Espanya no és un exemple d'aquesta excel.lència educativa, d'aquesta avantguarda pedagògica mundial. Malgrat això, podem afirmar: Suècia i Espanya tenen una característica comuna. Serveixi la següent cita a mode d'avís per a navegants:

\begin{abstract}
A Suècia, una de les obsessions globals en moltes escoles és aconseguir els seus 'valors fonamentals' correctes. Aquests valors sempre fan un aspecte impressionant, però són així mateix molt imprecisos. Una vegada tenen els valors correctes, els líders escolars assumeixen que l'èxit vindrà a continuació. L'aspecte que fan les escoles sembla que compten molt més que l'educació actual. Les persones que gestionen les escoles acaben assignant menys temps i recursos a ensenyar i aprendre, i més [temps i recursos] a exercicis per polir la imatge. Les escoles es converteixen en màquines per persuadir els altres que els infants estan obtenint una bona educació, enlloc que siguin institucions per educar els infants. (Alvesson i Spicer, 2016, p. 87) [La traducció és meva].
\end{abstract}

Aquesta és una última advertència que plantejo, i que considero molt necessària. Per estar preparats. Per estar en guàrdia. Per poder decidir de manera conscient com volem fer la nostra feina. Per així nosaltres els professors (i els mestres, i també els entrenadors) puguem albirar la decisió ètica que ens convoca. Per aleshores poder dir no a la possibilitat -ben a la vora com una invitació enverinada- de fer-se el desentès, acció que també podem expressar dient: fer el suec o fer l'andorrà. Un clam a no desentendre'ns, especialment -encara que no tan sols- de l'avaluació en l'àmbit de l'ensenyament a secundària. 


\section{Referències}

Alvesson, M. i Spicer, A. (2016) The Stupidity Paradox: The Power and Pitfalls of Functional Stupidity at Work. Londres, Profile Books.

Bermejo, J.C. (2009) La fragilidad de los sabios y el fin del pensamiento. Madrid, Akal.

Cercós, R. i Brasó, J. (2019) «Filosofia de l'educació cinquanta anys després del Maig del 68». Temps d'Educació, 56, p. 7-16.

Diem, C. (1966) Historia de los deportes. Barcelona, Lluís de Caralt Editor, 2 volums.

Enkvist, I. (2006) Repensar la educación. Madrid, Ediciones Internacionales Universitarias.

Enkvist, I. (2014) Educación: Guía para perplejos. Madrid, Ediciones Encuentro.

Fernández, C.; García, O.; Galindo, E. (2017) Escuela o barbarie: entre el neoliberalismo salvaje y el delirio de la izquierda. Madrid, Akal.

Freud, S. (2007) El porvenir de una ilusión. A Obras completas (Tom 8). Madrid, Biblioteca Nueva, p. 2961-2992.

Furedi, F. (2004) Therapy Culture. Cultivating Vulnerability in an Uncertain Age. Londres, Routledge.

Furedi, F. (2009) Wasted. Why Education Isn't Educating. Londres, Continuum Books.

Furedi, F. (2018) Qué le está pasando a la Universidad: un análisis sociológico de su infantilización. Madrid, Narcea.

Gavira, L. (2012) «La gestión terapéutica de la cultura: una nueva fórmula de disciplina social». Revista Andaluza de Antropología, núm. 4, p. 147-164. Disponible a: https://cercles.diba.cat/documentsdigitals/pdf/E140043.pdf [Data consulta 22.7.2020].

Hirsch, E.D. (2012) La escuela que necesitamos. Madrid, Ediciones Encuentro.

Jackson, Ph. (1992) La vida en las aulas. Madrid, Ediciones Morata.

Juanatey, L. (2015) Qué pasó con la enseñanza. Elogio del profesor. Madrid, Los Pasos Perdidos.

López Gómez, P. (2018) Lo que estamos construyendo. Consideraciones sobre los verdaderos problemas y las falsas soluciones de la enseñanza española del siglo XXI. Madrid, Verdana Servicios Editoriales.

Luri, G. (2019) La imaginación conservadora. Una defensa apasionada de las ideas que han hecho del mundo un lugar mejor. Barcelona, Ariel.

Luri, G. (2020) La escuela no es un parque de atracciones. Una defensa del conocimiento poderoso. Barcelona, Ariel.

Llovet, J. (2011) Adéu a la Universitat. L'eclipsi de les humanitats. Barcelona, Galàxia Gutemberg.

Mertanen, K. i Brunila, K. (2017) «Prison Break. Education of young adults in closed prisons - building a bridge from prison to civil society?». Education Inquiry, 9, 2, p. 155-171. Disponible a: https://www.tandfonline.com/doi/full/10.1080/20004508.2017. 1380478 [Data consulta 22.7.2020].

Moreno Castillo, R. (2006) Panfleto antipedagógico. Barcelona, El Lector Universal.

Moreno Castillo, R. (2008) De la buena y la mala educación. Reflexiones sobre la crisis de la enseñanza. Barcelona, Los libros del Lince.

Moreno Castillo, R. (2016) La conjura de los ignorantes. De cómo los pedagogos han destruido la enseñanza. Madrid, Editorial Pasos Perdidos. 
Moreno Castillo, R. (2019) Los griegos y nosotros: De cómo el desprecio por la Antigüedad destruye la educación. Madrid, Fórcola Ediciones.

Morin, L. (1975) Los charlatanes de la nueva pedagogía: Perplejidades de un joven profesor. Barcelona, Herder.

Navarra, A. (2019) Devaluación continua: Informe urgente sobre alumnos y profesores de secundaria. Barcelona, Tusquets.

Orrico, J. (2016) La tarima vacía. Sevilla, Editorial Alegoría (Callejón del Libro SL).

Ortega, E. (2020) «De la cura i la pervivència de la imaginació conservadora». Temps d'Educació, 58, p. 249-253.

Pennac, D. (2008) Mal d'escola. Barcelona, Editorial Empúries.

Pérez Gordillo, V. (2019) La dictadura del coaching: Manifiesto por una educación del yo al nosotros. Madrid, Akal.

Postman, N. (1990) Divertim-nos fins a morir. El discurs públic a l'època del «show-business». Barcelona, Llibres de l'Índex.

Postman, N. (2018) Tecnópolis: La rendición de la cultura a la tecnología. Barcelona, Ediciones el Salmón.

Prats, E. (2015) Teorizando en educación: entre erudición, poesía y opinionitis. Barcelona, Editorial UOC.

Rodríguez Prada, J.R. (2012) Conflicto y reforma en la educación (1986-2010). Los años decisivos: de la rebelión estudiantil a las consecuencias de la LOGSE. Madrid, Traficantes de sueños.

Royo, A. (2016) Contra la nueva educación. Por una enseñanza basada en los conocimientos. Barcelona, Editorial Plataforma.

Ruiz Paz, M. (2000) Los límites de la educación. Madrid, Grupo Unisón Ediciones.

Ruiz Paz, M. (2003) La secta pedagógica. Madrid, Grupo Unisón Ediciones.

Salvador, G. (2004) El destrozo educativo. Madrid, Grupo Unisón Ediciones.

Sánchez Tortosa, J. (2019) El culto pedagógico: Crítica del populismo educativo. Madrid, Akal.

Standish, A. (2012) The False Promise of Global Learning. Why Education Needs Boundaries. London/New York, Continuum International Publishing Group.

Tejedor, C. i Bonete, E. (2006) ¿Debemos tolerarlo todo? Crítica del «tolerantismo» en las democracias. Bilbao, Desclée De Brouwer.

Trojanow, I. (2018) El hombre superfluo. Barcelona, Editorial Plataforma.

Valdecantos, A. (2014) El saldo del espíritu. Barcelona, Herder

Valenciano, M. (2019) «La idea de participació en el reglament de minibàsquet: anàlisi conceptual i proposta pedagògica». Temps d'Educació, 57, p. 193-215.

Valenciano, M. (2020) «Aportacions inicials respecte Pragmatics of Human Communication en la confecció d'una pedagogia normativa, acompanyades d'algunes reflexions al voltant d'una ètica cibernètica». Dins del Seminari Bateson, Teoria de la Comunicació Humana i pedagogia (19 de febrer). Facultat d'Educació, Universitat de Barcelona. Seminari amb el suport del GREEPS (Grup de Recerca en Pensament Pedagògic i Social) i del Departament de Teoria i Història de l'Educació.

Wacquant, L. (2004) Entre las cuerdas: Cuadernos de un aprendiz de boxeador. Madrid, Alianza Editorial. 

cación y el control de datos del sistema educativo cuando los hechos ya no cuentan.

Resumen: En este texto ordeno algunas consideraciones sobre los efectos en la enseñanza obligatoria de las medidas para hacer frente a la situación generada por el COVID-19. Menciono que las medidas fueron anunciadas como pedagógicas, aunque de hecho son medidas con una marcada raíz económica y política. Una de las procedencias de estas consideraciones son algunos comentarios dirigidos al alumnado de la clase de la asignatura Economía de la educación durante el confinamiento. Una segunda procedencia de estas reflexiones será la revisión de las ideas recogidas para la exposición de un estudio de caso, destacando algunos de los puntos relacionados con la evaluación. Esta segunda precedencia está relacionada a mis experiencias profesionales en un centro público de secundaria a partir del 13 de marzo de 2020, así como también un muy especial comentario sobre el discurso acerca de la tecnología. A continuación, para pensar los males de la escuela contemporáneos propongo un paseo por las aulas a partir de diferentes referencias bibliográficas. Finalmente, rubrico mi análisis con algunos comentarios finales.

Parlabras clave: Evaluación educativa, políticas del confinamiento, neoliberalismo, tecnología, escuela contemporánea, teoría de la educación.

\section{L'évaluation confite, le discours actuel sur le rôle de la technologie dans l'éducation et la maîtrise des dommages causés au système éducatif catalan, lorsque les faits ne comptent plus. Une tentative d'analyse de l'enseignement secondaire pendant le confinement}

Résumé: Dans ce texte, je passe en revue quelques considérations autour des effets produits sur la scolarité obligatoire par les mesures visant à faire face à la situation générée par le COVID-19 et les politiques de confinement. En l'occurrence, je cite des mesures qui ont été annoncées comme étant pédagogiques, mais en précisant qu'en fait, il s'agit surtout de mesures de nature profondément économique et politique. Ces considérations proviennent, d'une part, de certains commentaires adressés aux élèves de la classe d'Économie de l'éducation pendant le confinement ; et, d'autre part, ces réflexions seront étayées par les idées recueillies dans une étude de cas, qui mettent en évidence certains des points liés à l'évaluation. Ces dernières réflexions renvoient à mes expériences professionnelles dans un établissement public d'enseignement secondaire à partir du 13 mars 2020, ainsi qu'à un commentaire centré sur le discours autour de l'usage de la technologie. Ensuite, pour réfléchir aux maux actuels de l'école, je propose de revisiter les salles de classe à partir de différentes références bibliographiques sélectionnées en vue d'établir éventuellement un futur guide de lecture. En conclusion, je termine mon analyse par quelques commentaires.

Mots clés: Évaluation éducative, politiques de confinement, néolibéralisme, technologie, école contemporaine, théorie de l'éducation.

\section{The sweetened assessment of the role of technology in education and the con- trol of the damage to the Catalan education system when the facts no longer count. Rehearsing an analysis of secondary education during confinament}

Abstract: In this article I put in order some considerations about the effects on compulsory education of the actions for dealing with the situation generated by COVID-19 and the lockdown policy. Although the actions taken are considered as pedagogical, they are in fact actions with clear economic and political roots. One of the origins of the considerations in this article are some remarks directed to university students in the Economy of Education subject during the lockdown. A second origin for these reflections is the review of ideas brought together for a case study, highlighting certain points related to assessment during the lockdown. Specifically, this case study brings together my professional experiences in a public secondary school, especially after 13 March, 2020. I discuss the discourse on the use of technology in particular. Afterwards, to think about the problems facing the contemporary school, I propose a tour of the classrooms based on bibliographical references. This part of the article is constructed as a selection of readings (which in the future can evolve into a reading guide). Finally, I complete my analysis with some last comments.

Keywords: Educational evaluation, lockdown policies, neoliberalism, technology, contemporary school, education theory. 